\title{
On Interaction of Educational Environments of Different Levels
}

\author{
Boris Evgenievich Starichenko \\ Alexander Vladimirovich Slepukhin \\ Liubov Vladimirovna Sardak \\ Department of Information and Communication Technologies in Education, Ural State Pedagogical University, Yekaterinburg \\ Russian Federation, Correspondence: Boris Evgenievich Starichenko, 620017, Kosmonavtov Str., 26 \\ Yekaterinburg, Russian Federation; E-mail: b.starichenko@gmail.com
}

Doi:10.5901/mjss.2015.v6n5s4p486

\begin{abstract}
The article is devoted to the discussion of the questions connected with the construction and the organization of interaction of information educational environments of various levels: learning management system of educational institution (LMS), personal teacher environment (PTE) and personal learner environment (PLE). It is shown that LMS cannot provide support of the solution of a number of didactic tasks (joint educational activity, access to tools, cross-platform software, creation of the personal educational space available after completion of study, etc.). As a solution of the present situation the creation of virtual personal environments for the teacher and student is offered, within which, on the one hand, long storage of educational information (i.e. technological support of the thesis "Long life education"), and, on the other hand, realization of various forms of joint educational activities are possible. The article analyzes the basic terminology and concepts, offers their clarification in the context of developing the idea. The question of the organization of optimum interaction between educational environments of various levels (LMS, PTE and PLE) has to be solved by the teacher depending on features of the course of study and the training methods used. In particular, the selection of two basic schemes of such an organization is considered and justified. The approbation of the stated approach was made when teaching the disciplines "Computer mathematics" and "Computer graphics" to students-future IT specialists. The expediency and the ability to create virtual personal training by teachers and students are shown, and also the examples of their interaction with each other and the university LMS are given.
\end{abstract}

Keywords: information educational environment, personal educational environment, Learning Management System

\section{Introduction}

\subsection{Relevance of the Problem}

One of the main technological approaches providing the use of information and communication technologies (ICT) in educational process of higher education institutions is now considered the deployment (creation) of the information educational environment on the basis of one of LMS (Learning Management)-Moodle, BlackBoard, Sakai, eLearning $4 G$, etc. in them. The justification of need of the organization of such environments, their structure, operating conditions and methods of the organization of educational process on their basis are described in a set of works by theoretical (Dayana et al., 2010; Karrer, 2008; Martin, 2007, etc.), technological (Atanasyan, 2009; Vasilchenko, 2012; Duhnich, 2011; Kuharenko, 2011; Malkova \& Feshchenko, 2013; Starichenko, 2013; Starodubtsev, 2012; Chatti, 2010; Harmelen, 2009; Wilson et al., 2006, etc.) and methodical character (Korovin, 2011, etc.).

From the positions of the teacher, LMS is urged to realize the following main functions of the organization of educational process:

- Placement of educational content and operational students and teachers access to it;

- Differentiation of access to content and other resources;

- Management of training process on the part of the teacher;

- Expeditious communication of the teacher and students.

LMS possesses a number of indisputable benefits and advantages in comparison with the earlier existing "precomputer" schemes of the organization and management of educational process: completeness and simplicity of updating the content, opportunity and efficiency of remote access to it, efficiency of communication, electronic formats of storage of documents and standardization of representation of training courses. It should be noted, however, that the 
training model from the point of view of participants' roles in educational process in LMS repeats the traditional-the teacher is active, he has to:

- Collect (to prepare) educational content and to provide access for students to it;

- Offer sources of educational information;

- Establish the schedule and an order of studying of discipline;

- Whenever possible-provide a training individualization;

- Operate the training course on the basis of results of a constant control of success of digestion of material;

- Assess the results of training;

- While the learner appears to be the performer of the set of educational tasks with the rights to:

- Receive educational content without possibility of its change and addition;

- Carry out educational actions according to the schedule of educational process and to submit to the teacher reporting materials within established periods and in the demanded formats;

- Address the teacher with inquiries.

This organizational scheme LMS allows to unify the requirements to structure of methodical and organizational support of educational process in higher education institution and to standardize the representation of training materials (for example, in SCORM format)-these moments should be considered as definitely positive. The creation of the unified information educational environment of higher education institution, as shown in many works (Atanasyan, 2009; Korovin, 2011; Starichenko, 2013, etc.), is an obligatory stage of introduction of information educational technologies in educational practice.

\subsection{Contradiction}

However, in dealing with a number of didactic problems LMS, functioning on the basis of client-server solutions can be inconvenient both for the teacher, and for the student, as:

- They are limited to a tool kit; and the LMS services, as a rule, are not expandable; at this LMS doesn't contain software tools for performance of educational tasks-basically, the most demanded tools in it are the ones of organization of operational file sharing and storage, news, communication;

- In the general access only the teacher has the rights of placement of documents;

- The opportunity for students' collaboration over the document, as well as implementation of the project or mutual discussion are not provided; as an exception it is possible to mention the wiki mechanism which is realized in many LMS, however it is used extremely seldom, in particular due to the fact that the developed materials are placed on the LMS server and are available only to the registered users;

- As a rule, only the students studying discipline at present have access to resources and discussions; upon completion of a course a person loses the possibility of access to the discipline site, and after the course completion in higher education institution-even to all its materials placed in LMS;

- The tools and the LMS interface are not focused on modern mobile hardware-software decisions which have the touch-interface and assume use of cloud ideology of interaction of the client and information when content and means of its processing are located on the remote server;

- LMS has its own interface, which has nothing to do with the most popular information and social services; as a result, users accumulate a sufficiently large number of accounts (logins) and passwords to access the different non-interactive portals and global Internet services, including the ones for educational purposes.

The listed (and other similar) circumstances, on the one hand, and the need in developing independence and activity of students, raising awareness of the process of cognition, on the other hand, led to the emergence of an alternative (in relation to the LMS) approach, which in the last few years has been actively discussed in the pedagogical publications (Attwall, 2007; Wilson et al., 2006; Cann, 2011; Harmelen, 2009; Chatti, 2010; Starodubtsev, 2012, etc.) and practically implemented (Atanasyan, 2009; Vasilchenko, 2012; Alsagoff, 2011; Chatti, 2010; Harmelen, 2009, etc.) The approach consists in the construction of Personal Learning Environment of the student (PLE).

\subsection{Approaches to Problem Solving}

It is offered, guided by modern hardware decisions, on the basis of the existing registration for subjects of educational process on the Internet to create a virtual space for an exchange and storage of educational information, ensuring communication, planning of activity, collecting and storage of results of training. For the organization of such space it is 
expedient to use the cloud technologies realized on the Internet, and also by means of the Web 2.0 services. PLE is built and developed by a trainee, adding in it all the components necessary for him to master the educational programs informative, instrumental, communicational and so forth. It is certainly expandable-in process of emergence of new disciplines the student creates in it some new sections corresponding to them. The significant argument in favor of such environment is the possibility of its development and use also after graduation from the educational institution which provides practical support of the concept of the distributed lifelong learning. Technologically PLE can be organized in the form of a personal page on a social network, a blog, a twitter or a site.

However, in an educational institution the process of development of the discipline is organized and controlled by the teacher. Consequently, the teacher requires its own virtual environment through which he could interact with personal students' environments, as well as implement joint forms of training activities. Personal Teaching Environment (PTE) is formed by the teacher when choosing necessary network services and tools and creating the discipline blog. All allowed participants can take part in the work of such a blog (and, the circle of these persons can be much wider, than only the students studying discipline at present, for example, students of senior courses, teachers, graduates, students and teachers of other higher education institutions and so on). Certainly, the teacher has a possibility to place all necessary training materials or links to them and necessary cloud tools in the environment. PTE realizes the idea of creation of thematic network community which possesses not only informative, but also some motivational appeal to modern youth.

\subsection{Main Hypothesis}

Undoubtedly there is no well-established interpretation of terms settled definition of the terms PLE and PTE, understanding of their didactic appointment-thus, the comparative analysis of these concepts and possible technological decisions for their realization will be provided below. However, the aspect which we want to focus attention on in this article is that PTE cannot replace LMS completely (as some radical authors claim). The matter is that the teacher in the educational activity is obliged to follow certain standards according to the contents, methods of training and assessment, presentation of educational and methodical materials, etc. Besides, the set of materials ensuring educational process is the resource property of educational institution, but not of the certain teacher and, therefore, has to be placed in its information storage. LMS in a higher education institution is necessary, and now it is not possible or expedient to reject it. In this regard there are some content, methodical and technological problems (from the point of view of efficiency of educational process)-how to provide an optimal combination of use of LMS-PTE-PLE? In the work the example of a possible solution when studying discipline "Computer graphics" by future IT specialists in higher education institution is given.

\section{Analysis of Basic Terms}

\subsection{Concept of Information Educational Environment}

In the context of the discussed problem a concept "educational environment" is certainly initial in the hierarchy of concepts. On the basis of synthesis of the definitions which are available in pedagogical literature we find it possible to accept the following treatment: the educational environment is a system of pedagogical, psychological, economic, technological and some other conditions which create the possibility to achieve the set of didactic objects and to disclose the abilities and personal features of learners. The essential component of the educational environment is the information educational environment (IEE) which we treat as set of information support (substantial, methodical, standard and legal, organizational) - content-and the means of communication necessary for realization of educational process and the participants satisfying all related information requirements (trainees, teachers, authoritiess).

Within the described research the classification of IEE by ownership is represented-it may belong to the educational institution or be personal; from which, in turn, it is necessary to distinguish the environment of a teacher and the environment of a student.

In relation to a student (as to a consumer of educational services) an educational institution provides realization of an educational program according to some standard or other principles of creation of the plan of training. To support this process the educational institution has to have IEE containing the full information content necessary for the student to master an educational program.

The materials of such IEE are the property of an educational institution and, naturally, have to be kept in its information storage. This provides standardization of representation of training and organizational materials, possibility to control their existence and the contents, continuity, unification for different teachers and so forth. The similar IEE is 
realized technically by spreading Learning Management System (LMS)_some popular platforms are Moodle, Black Board, Sakai, e-Learning $4 \mathrm{G}$ and the like.

\subsection{Trends in Defining "Personal Educational Environments"}

The possibilities to use virtual educational personal environments in learning process as an alternative to LMS are discussed lately, built, in particular, on the basis of Web 2.0. The definitions of the term "personal educational environment" by different authors vary significantly; the notions of private, individual and personal educational environment are used as synonymous ones (often without proper understanding and justification).

On the basis of content analysis of approaches to the definitions of the above-mentioned terms we can distinguish the following trends of defining "personal educational environments" (or learning/teaching environments): The environment as idea of realization of new educational technologies, so, for example, Attwell (2007) defines the personal educational environment as the idea integrating long informal training, style of training, new approaches to assessment, cognitive tools; thus one argument in favor of the personal educational environment is development of educational technologies which can show how technologies are used in training and which will allow trainees to define the educational opportunities, and also to create, summarize, reproduce and share material; the environment as set of tools for the solution of educational tasks, in particular, most of supporters of this approach places emphasis on a technical (resource) component or its use:

- Set of tools, communities and services on which the individual educational platforms are based, intended for use by learners to which independent management of the training and independent setting of the educational goals is provided (Duhnich, 2011);

- The tool which allows trainees to participate in the distributed environment consisting of a network of people, services and resources, and also a tool for a personal educational network for interaction with colleagues on joint activity (Kukharenko, 2011);

- The open socio-technichal system formed by a finite set of functional elements (services, gadgets, widgets, means of communication) and their connections allocated by the individual in information saturated environment; purpose of realization of dual nature of the activity as a supplier and a consumer of educational services during lifetime and in the context of professional activity (Starodubtsev, 2012);

- The free use of a set of convenient services and tools which belong to separate trainees and are operated by them (the approach demands a social context, providing means for connection with other personal spaces with the aim of effective exchange and joint creation of new knowledge) (Chatti, 2010);

- The environment filled according to requirements and interests of a trainee, assuming an independent choice and a flexible use of tools for cognitive activity (Martin, 2007);

- The interaction environment, set of tools to support the purposes of training (Wilson et al., 2007);

The environment as set of methods of training (technological component), so, for example, Attwell (2007) defines the personal environment of training as a set of methods which in total represent technology of informal training, styles of training, new approaches to an assessment.

The environment allowing to realize separate types of educational activity:

- System which helps the trainees to control and operate their own training (Malkova \& Feshchenko, 2013; Cann, 2011);

- The process of the organization and visualization of a flow of educational information (Malkova \& Feshchenko, 2013, Cann, 2011);

- The system which helps students to operate their own training, including ensuring support of pupils in definition of their own purposes of training, management of the training, management of the contents and process of training, interaction with other trainees in the course of study, and, thereby, achievement of the objectives of training (Harmelen, 2009);

The environment as a system (set) of structural components of educational process, so, for example, Vasilchenko (2012) defines the personal educational environment as the set of the contents, forms, methods, means of training and educational communications received from the information and communication educational environment by adaptation according to the purposes, the contents and the planned results of training, requirements and abilities of the trainee and acting as means of personalization. 


\subsection{Concept of Personal Learning Environment}

In the considered examples and other works the authors use the same abbreviation (PLE) for designation as circles of the teacher, and the circle of the student that is supposed not quite successful and convenient for understanding. Taking into account distinctions of appointment, structure, the contents, tools, services and other components it seems justified to us to part representation of personal IEE of the teacher and student-the first we will designate PTE (Personal Teaching Environment-the personal environment of training (teacher)), the second-PLE (Personal Learning Environment-the personal educational circle (student)).

We will understand by personal learning environment of the student (PLE) the personal information resource, created in virtual space, supported and developed by the student.

As it is specified in the numerous works devoted to technological aspects of creation of PLE (Duhnich, 2011; Kuharenko, 2011; Malkova \& Feshchenko, 2013; Asuncion et al., 2010; Attwell, 2007; Chatti, 2010; Harmelen, 2009; Wilson et al., 2006, etc.), its components can be:

- Training materials in electronic formats of representation;

- Cloud tools and services necessary for performance of educational tasks;

- A reference system on educational Internet resources;

- Communication services.

PLE is designed by the student-he independently defines the contents, convenient for him, and representation of materials and other components. In an ideal the resource has to be unified for all types and forms of educational activity, for all disciplines. Thus influence of the teacher viewed in the formulation of recommendations about the creation of an environment segment relating to specified discipline.

That circumstance is believed to be important that the student can allow access to some elements of the resource to the teacher and fellow students and, in turn, to get access to PLE of other students and to the teacher's IEE. In other words, through interaction of PLE and PTE the thematic network community which purpose is mastering a subject is formed.

The personal environment of training of PTE is the set of components of educational process (the contents, forms, methods and tutorials, means of communication) created, placed and maintained by the teacher in virtual space providing individual and joint educational activity of students in the course of development of discipline.

\subsection{Technological Approaches to Realization of PTE}

The analysis of information sources allows allocation of three groups of the main technological approaches to realization of PTE.

According to approaches of the first group of the researchers allocating, first of all, functional criteria of the environment, the personal educational circle of the teacher includes:

a) All primary activities with educational information, formation (development) of competences and competencies, the organization of assessment, creation of a diagnostic background, personalization (individualization) of training;

b) Kinds of activity performed as a consumer and as a producer of educational services, and also professionally regulated and informal, individual and personal educational and/or social activity (according to van Harmelen, 2009).

Supporters of the second group of the approaches considering, first of all, technical, tool (resource) filling of the environment claim that the personal educational environment has to be under construction not only on LMS basis, and on a combination of such systems and:

a) Personal computers, access devices to learning environment, servers, special devices (Harmelen, 2009).

b) Means of communication with the Internet resources:

- Mobile phone, tablet, netbook, personal computer, means of wireless access to a global network;

- Local (on the personal computer or the server) and distributed (on services of the Internet) bases of storage of information and educational materials;

- Means of identification of users and administration by the created personal site, the blog, community, and also software of creation of content with educational properties (Duhnich, 2011);

c) The Web 2.0 services and the educational tools including, for example, a text editor (Nisus Writer Express), Email the client (Mac Mail), the daily log (iCal with communication with the website), podcasts (Garage Band), 
Audio for creation, the video editor for preparation of multimedia presentations (iMovie), the web blog the client (Ecto), a control system of content of the website (Jumbla), the personal web blog (Knotes), the photo editor (iPhoto), means of publications of photos (Flickyr), service of an exchange of bookmarks (Delicio-us), service of the publication of podcasts (Jumbla), the editor for preparation of presentations (Keynote), the news reader (Net Newsreader), means of a video conferencing (Skype), etc., (Attwell, 2007; Chatti, 2010; Dayana et al., 2011; Karrer, 2008; Park et al., 2011, etc.);

d) Dloud services (Asuncion et al., 2010, etc.).

Supporters of the third group of approaches point to creation and need of application of program covers of personal educational environments, such, for example, as Epsilen Environment (Jafari, 2006), PLEF-Personal Learning Environment Framework (Chatti, 2010), PLEX-Personal Learning Environment project (Martin, 2007), Symbaloo (Ash, 2013), The Manchester Personal Learning Environment (Harmelen, 2009, etc.)

Thus, the teacher as the person who directly organizing educational process and operating it has opportunity to use IOS of three levels-LMS, PTE and PLE. In this regard there is a question of design of their interaction which would be optimum for this contents and conditions of training and would provide effective achievement of the set didactic objects.

\section{Method}

\subsection{LMS Features}

It will be a question of possible schemes of interaction of IEE of various levels which the teacher depending on specifics of the maintenance of a subject matter and the used training methods can organize.

It should be mentioned that as at "traditional" creation of IEE on a basis of LMS it is possible to allocate personal circles of the teacher and student (the truth, such approach wasn't applied earlier). Thus it is necessary to take into consideration a functional purpose and features of LMS from the point of view of realization of educational process by the teacher:

- Storage of organizational and methodical materials (program of discipline, schedule of studying, terms and forms of the reporting and so forth);

- Storage of the main educational and methodical information necessary for development of discipline (electronic educational and methodical complex, training course);

- Storage of links to additional sources of information;

- Storage of materials for educational independent work (group and individual);

- Realization of remote delivery of educational tasks and reception of results of their performance by students;

- Automatic maintaining of register of performance by students of educational tasks.

\section{2 "Closed" Interaction Scheme LMS-PTE-PLE}

Within LMS personal environments of the teacher and students are under construction. Thus PTE represents the website of a subject matter on which the teacher publishes materials of organizational and educational purpose, and also connects necessary tools from provided in LMS. Access to the site is allowed to the registered users, usually, with the rights only of reading of information. The personal circle of the student is also the site with access to which of only his owner. On this resource the student can place his own materials; it has links to the sites of all disciplines to which the student entrance is allowed. For the solution of educational tasks the student uses program tools which do not enter LMS and has to be located at its workstation. The student with the use of this or that communication service transfers the individual report on performance of a task to the discipline site. Joint educational activity of students on the site of discipline cannot be organized. It is illustrated by the scheme in Figure. 1 which is possible to call "Closed" on the basis of that circumstance that personal IOSs and their interaction is realized within some resource with limited access. 


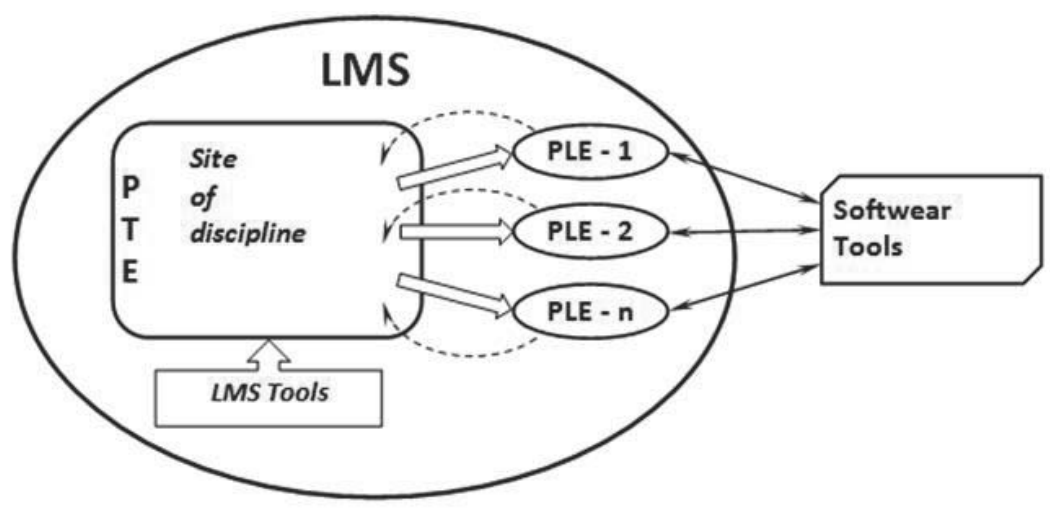

Figure 1. "Closed" scheme of interaction of LMS-PTE-PLE

This scheme, certainly, has the right for existence; it is expedient to use it, if:

- Individual (not group) methods of the organization of educational activity are applied;

- Educational tasks have individual (not group) character;

- Technique of training provides the frequent reporting with big statistics of grades;

- Performance of educational tasks requires the specialized software which has to be installed at workstations.

The examples of disciplines, expedient to be taught according to the described scheme, are mathematics, physics, chemistry, information technologies, informatics and so forth, i.e. the disciplines including laboratory or practical training.

As an alternative to "Closed" it is possible to offer the scheme which is based on complex use of cloud services for information processing, its storage, and also communication of subjects of educational process-we will call it "Cloud". Thus the PTE functions are:

- Ensuring joint discussion of questions of studying of discipline with the help of the integrated means of communication (a chat, a forum, a videoconference, etc.);

- Organization of joint educational activity of students (development of the general documents, projects, mutual reviewing, etc.)

- Management of educational activity (so-called Time Management-a calendar of studying of discipline with the notification of students);

- Ensuring the access to the PTE resources from various devices-a computer, a tablet PC, a smartphone, etc. (crossplatformennost of users).

PTE is organized and presented by the teacher in the form of a personal resource in virtual space (for example, in the form of the blog, virtual group or community), PLE is made out by the student also in the form of a cloud information resource. As the main PLE functions it is necessary to consider:

- Organization and support of a personal component of the educational circle of the student;

- Possibility of connection to PTE, PLE of other students and participation in individual and joint educational activity.

\section{3 "Cloud" Interaction Scheme LMS-PTE-PLE}

The "Cloud" scheme of interaction of LMS-PTE-PLE is submitted in fig. 2. In particular, it reflects the fact that even when using cloud PTE and PLE the environment of educational institution (LMS) is necessary for placement of the site with the main educational and methodical complex. In other words, in PTE two components-one-PTE-L, as well as in the scheme "Closed" are allocated, settles down in LMS; another-PTE-C-is in a cloud. PTE-C can be connected with PTE$\mathrm{L}$ a reference system; on it the part of educational information is also placed. 


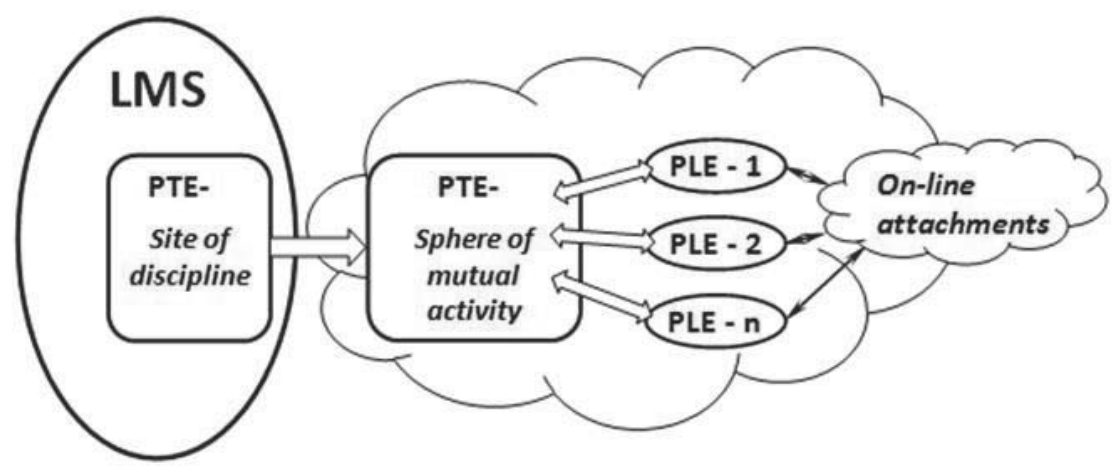

Figure 2. "Cloud" scheme of interaction of LMS-PTE-PLE

Educational tasks (individual or group) are placed on PTE-C; for their fulfilment on-line-applications can be used (that, in particular, provides possibility to use mobile devices when training).On PTE-C the area to which all participants of community from the PLE have access is provided. It allows organize joint educational activity of students in the form of group work on the document or the project, cross reviewing and evaluation or discussions. Therefore, application of the "Cloud" scheme is justified when educational tasks have analytical, creative character at their group performance and discussion of results.

The described schemes-"Closed" and "Cloud"-should be considered as the limit. Obviously, it is possible to represent a range of intermediate options, for example, when for performance of tasks not cloud, but usual (located at workstations) tools are used or studying of discipline doesn't include students' collaboration. It is important that existence of a wide range of cloud services provides flexibility of construction and interaction of IEE of various levels.

\section{Results}

By way of illustration to the ideas stated above we will consider the organization of interaction of LMS-PTE-PLE when studying discipline "Computer graphics" by students of pedagogical higher education institution. The discipline "Computer graphics" allows form not only students' knowledge and abilities to use tools of systems of computer graphics, but also common cultural knowledge of aesthetics, composition, colouring. The latter are formed in the process of the analysis and comparison of ready works or in the course of creation of own work with further correction according to responses.

As the joint activity of students in the form of discussions and mutual reviewing is supposed when studying discipline, the choice of the "Cloud" scheme of interaction seems obvious. PTE consists of two components-the discipline site in LMS (PTE-L) and network community on the basis of cloud service (PTE-C). In the course of the discipline three big substantial modules are allocated: theoretical (technological fundamentals of computer graphics), practical (mastering of tools) and creative (creation of student compositions according to the set scenario). Thus, educational content is presented by the electronic training materials placed in PTE-L (in LMS Sakai). PTE-C was implemented as closed community for studying computer graphics on the basis of cloud services Google + . Services provided for distribution of educational tasks, organizer for managing educational work of students, collaborative chat and forum.

A very important component of PTE was the area where all students could place the results of their work. Exactly thanks to it, all students can examine works of each other, discuss them and estimate. The existence of such an area provides possibility of student interaction in the course of training and the organization of their joint educational activity. For example, in fig. 3 the gallery of the students' works performed in Salvador Dali's style is presented. The works are available to all participants of the community. For students it is a source of an exchange of ideas, a subject for polemic and assessment. On the basis of gallery works the teacher carries out discussion, joint with students, allocating successful and less successful decisions. He also focuses attention on technical elements of the images-dynamics, statics, a treatment of light and shade and the like. 


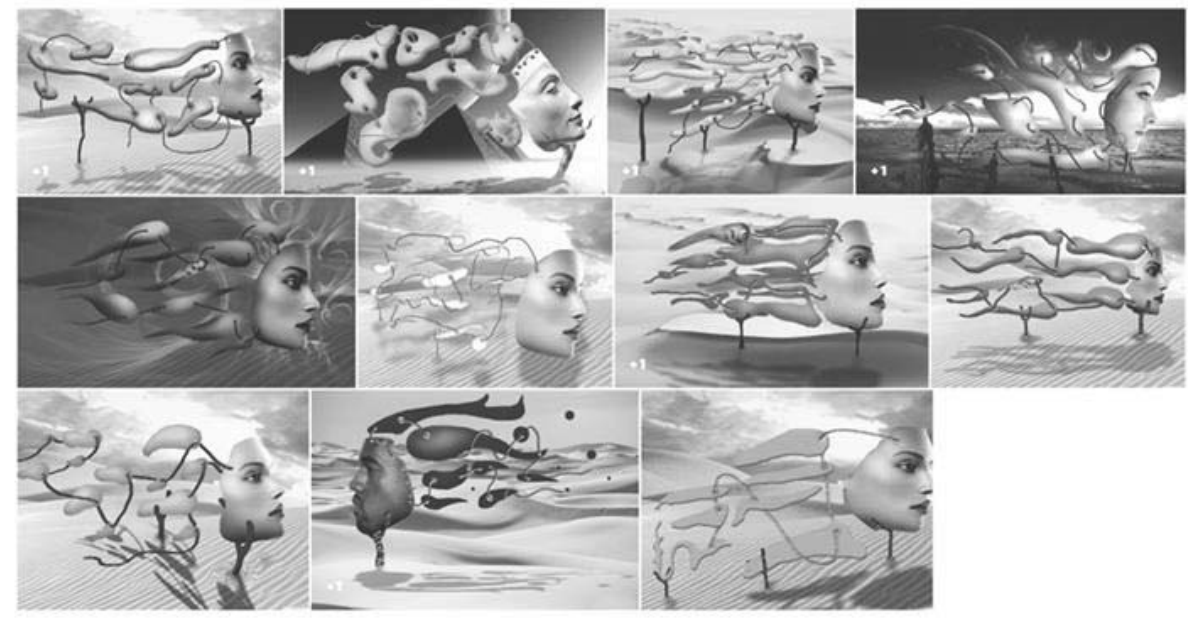

Figure 3. Example of gallery of students' creative works on the set subject

\section{Discussion}

Thus, PTE includes: the working training program, the schedule of control points, regulations of the organization of training, electronic training materials (texts of lectures, presentations, educational movies, texts of laboratory works, and the list of competitive creative tasks, system of internal and external hyperlinks on resources) and instruments of communication. Specifics of the content of discipline allow compensate partially the absence of the local software by its on-line analogues when performing educational tasks outside the lecture halls.

PLE contains all PTE elements and also all materials, available to the specific student, in a subject which the student independently selects and accumulates on the virtual disk. So, for example, students create the catalogue of the works, representing them in virtual photo galleries, for an assessment of quality of the performed work (according to an educational task).

The interaction of teachers and students is carried out:

- Individually by means of chat facility built into a cloud service, electronic mail received at registration on cloud services, as well as tools LMS;

- In the form of a panel discussion in the community and / or group; students, being members of the community, have the opportunity to communicate and share information.

Students receive tasks in the LMS and via the annunciation of the event in the community. Task submission is done with the help of the tool "Tasks" in the LMS-the links on graphic works displayed in the community gallery are attached while the task is submitted.

Thus, during the study of the discipline interaction information environments were organized, providing maximum use of their potential didactic possibilities. There were also practical advantages and disadvantages established proven patterns of interaction environments. Thus, when studying discipline the interaction of information environments was organized providing the maximum use of their potential didactic opportunities. Merits and demerits of the approved scheme of interaction of environments were also established practically.

It is necessary to emphasise the positive moments:

- All created works, samples, links to useful resources are collected and systematized in one place; continuous replenishment of the samples collection with students works;

- On discipline course completion the resource remains available to the student even after the termination of higher education institution;

- Simplicity of verification of graphic files, as delivery of identical works by students will be visible at once to all associates;

- Possibility of the organization of the built-in polls;

- Possibility to create ratings at works evaluation (popularity); 
- Opportunity to provide access to rather big files (more than $50 \mathrm{Mb}$ ) that is important during the work with graphic files;

- Cross-platform software;

- Adjusted design of a community subject.

Alongside with the positive moments also the negative ones were revealed:

- Partial, and at times full duplication of materials in LMS and in a cloud;

- Simultaneous authentication at least in two systems (in LMS and in a cloud) is necessary for work;

- The electronic register is filled in manually if there is no binding of each lesson to LMS.

\section{Conclusion}

This study allows us to conclude that the creation of personal educational environments by teachers and students and ensuring their interaction with each other and with the educational environment of the institution extends the circle of didactic problems solved with their help.

In particular, the organization of joint educational activity of students becomes possible as well as application of cloud tools, expansion of trainees circle, use of modern mobile hardware-software decisions in the course of training and so forth. The nature of environments interaction is defined by the teacher depending on content peculiarities of the taught subject and the used training methods.

We see the further development of ideas of this study in several directions:

- Identification of new training methods related to the possibility to organize joint students' training;

- Comparison of different cloud platforms in order to identify the optimal one in terms of convenience to create of the PTE and PLE environments;

- Study of the specifics of building PTE and PLE depending on the content of the studied discipline;

- Detection of the features of PTE and PLE construction when using mobile technologies in the organization of educational process.

Apparently, we should recognize that in development of information and communication technologies the tendency of addressing cloud-based solutions is obviously traced recently. In this regard it is possible to predict, as it has already happened to the previous technological innovations, that information educational technologies will also be oriented on active use of cloud services.

\section{Acknowledgments}

The work is performed according to the the Ministry of Education and Science of the Russian Federation; grant 2014/392, project 2039.

\section{References}

Alsagoff, Z. (2011). Empowering personal learning environments. Retrieved from http://deanships.jazanu.edu.sa/eld/Documents/ workshop/Empowering\%20PLE_Jazan.pdf

Ash, K. (2013). Personal Learning Environments' Focus on the Individual. Education week. Retrieved from http://www.edweek.org/ ew/articles /2013/05/22/32el-personallearning.h32.html

Asuncion, J. L. R., Lee, M., Rommel, M., \& Feria, P. (2010). Design and Implementation of a Cloud-based Personal Learning Environment. Retrieved from http://pleconference.citilab.eu/cas/wp-content/uploads/2010/09/ple2010_submission_23.pdf

Atanasyan, S. L. (2009). Formation of the information educational environment of pedagogical higher education institution: Thesis abstract of the doctor of pedagogical sciences. Moscow, RAE.

Attwell, G. (2007). Personal Learning Environments—-the future of eLearning? ELearningpapers, 2(1), 1887-1542. Retrieved from http:// www.elearningpapers. eu.media11561-1\%20(1).pdf

Cann, A. (2011). Personal Learning Environments, Personal Development Planning and Lifelong Learning. Retrieved from http://www.bioscience.heacademy.ac.uk/resources/projects/canndept.aspx

Chatti, M. A. (2010). Personalization in Technology Enhanced Learning: A Social Software Perspective (Doctoral dissertation). Germany: Aahena Univercity.

Dayana, A. H., Bilal, N., Ali, M., \& Yahaya, N. (2010). Personalized Learning Environment: New Trend in Online Learning. Retrieved from http://eprints.utm.my/14943/1/Personalized_Learning_Environment.pdf

Dukhnich, Yu. (2011). The personal learning environment-PLE. Retrieved from http://www.smart-edu.com/personalnaya-sreda-obuche niya-ple.html 
Jafari, A. (2006). Epsilen A connect EDU Company. Retrieved from http://corp.epsilen.com/

Feldstein, M. (2011). Market open source LMS in educational market of the USA. Retrieved from http://www.smart-edu.com/ razvivayuschiysya-rynok-Ims-michael-feldstein.html

Harmelen, M. (2009). The Manchester Personal Learning Environment. Retrieved from http://www.jisc.ac.uk/events/2009 /03/ngtip Imple.aspx

Karrer, T. (2008). Learning 2.0 Strategy: ELearning Technology. Retrieved from http://elearningtech.blogspot.com/2008/09/learning-20strategy.html

Korovin, S. V. (2011). Formation of the unified information educational environment as condition of development of professional competence of college students: Thesis abstract of the candidate of pedagogical sciences. Chelyabinsk: ChSPU.

Kukharenko, V. M. (2011). Personal learning environment. Retrieved from http://kvn-e-learning.blogspot.com/2011_03_01_archive.html

Kuts, E. V. (2013). Methodical approaches to use of the system of hardware and software providing realization of the hi-tech environment of educational institution (on the example of training of pedagogical and administrative staff): Thesis abstract of the candidate of pedagogical sciences. Moscow, RAE.

Kuvshinova, E. N. (2013). Methodical approaches in the field of use of the information and education environment at higher education institution when training students in planning and realization of independent educational activity (on the example of professional development of pedagogical staff): Thesis abstract of the candidate of pedagogical sciences. Moscow, RAE.

Malkova, I. Yu., \& Feshchenko, A. V. (2013). Design of learning environment and an individual educational profile by means of virtual educational networks in the conditions of introduction of new FGOS. Open and distant education, 2(50). 44-53.

Martin, M. (2007). Supporting Personal Learning Environments: A Definition of a PLE. Retrieved from http://michelemartin.typepad.com/ thebambooprojectblog/2007/08/supporting-pe-1.html

Park ,Y., Mi, H. G., \& Lee, R. (2011). Blogging for Informal Learning: Analyzing Bloggers' Perceptions Using Learning Perspective. Educational Technology \& Society, 14(2). 149-160. Retrieved from http://www.ifets.info/journals/14_2/13.pdf

Starichenko, B. E. (2013). Conceptual basics of computer didactics (Monography). Yelm, WA, USA: Science Book Publishing House.

Starodubtsev, V. A. (2012). Creation of the personal educational circle of the teacher of higher education institution: manual. Tomsk: Publishing house of Tomsk Polytechnical University.

Vasilchenko, S. H. (2012). Formation of the personal educational environment on the basis of information technologies for realization of individual trajectories of training (on the example of corporate training): Thesis abstract of the candidate of pedagogical sciences. Moscow, FIDE.

Wilson, S., Liber, O., Johnson, M., Beauvoir, P., Sharples, P., \& Milligan, C. (2006). Personal Learning Environments: Challenging the dominant design of educational systems. Retrieved from http://dspace.ou.n//handle/1820/727 